\title{
Carona UFMG: Investigando as Relações de Troca, Segurança e Recompensa no Desenvolvimento de uma Aplicação Móvel Voltada a uma Comunidade
}

\author{
Antônio Henrique Gonçalves Leite, Luiz Paulo Damilton Corrêa \\ Raquel Oliveira Prates, Fabrício Benevenuto, Pedro Olmo Vaz de Melo \\ ${ }^{1}$ Departamento de Ciência da Computação (DCC) \\ Universidade Federal de Minas Gerais (UFMG) - Belo Horizonte, MG - Brasil \\ \{antonioh, luiz.correa, rprates, fabricio, olmo\}edcc.ufmg.br
}

\begin{abstract}
Collaborative consumption applications have been increasingly used, with new proposals for the exchange of goods and services between users. But what are the users motivations to offer and use a particular service when an application is directed to a local community and there is no exchange of money? In this paper, we use the development of a new mobile application for carpooling in a Brazilian university to discuss this issue, based on the results of a survey $(n=$ 287) and considerations of the Brazilian literature about this subject. Thus, we have raised some considerations of reward, exchange and security, and present a new project implementation.
\end{abstract}

Resumo. Aplicações de economia colaborativa têm sido cada vez mais utilizadas, com novas propostas de mercado para a troca de bens e serviços entre usuários. Porém, qual a motivação dos usuários para ofertar e usufruir um determinado serviço quando uma aplicação é voltada a uma comunidade restrita e não há uma troca direta de moeda? Neste trabalho, tomamos como base o desenvolvimento de um novo aplicativo móvel para caronas em uma universidade brasileira para discutirmos essa questão, a partir de resultados de um questionário $(n=287)$ e considerações da própria literatura brasileira. Com isso, levantamos algumas considerações dos usuários sobre recompensa, troca e segurança, e apresentamos uma nova implementação de sistema.

\section{Introdução}

Economia colaborativa ou economia compartilhada (dos termos em inglês "collaborative consumption" [Rachel Botsman 2010] e "sharing economy” [Hamari et al. 2015]) é um modelo híbrido de mercado que foca no estabelecimento de redes pessoa-para-pessoa de compartilhamento de bens e serviços. Empresas que adotam este modelo não oferecem diretamente um bem ou serviço físico, mas proporcionam uma plataforma que permite que os seus clientes interajam entre si para a troca desses bens e serviços, servindo unicamente como mediadoras entre um ofertante e um demandante. Recentemente, este modelo tem se tornado popular graças ao surgimento e crescimento de plataformas como a Uber $^{1}$, para serviços de transporte, a Airbnb ${ }^{2}$, para hospedagens, e o TaskRabbit ${ }^{3}$, para

\footnotetext{
${ }^{1}$ https: / / www .uber.com/pt/

${ }^{2}$ https : / / www . airbnb. com.br/

${ }^{3}$ https: //www.taskrabbit.com/
} 
serviços domésticos. Essas aplicações permitem o contato real, fora do sistema on-line, entre pessoas que a princípio não se conhecem, em troca de um serviço que beneficia tanto o ofertante (motorista; anfitrião da hospedagem; prestador do serviço doméstico), que recebe, nestes exemplos, uma quantia em dinheiro, quanto o demandante (passageiro; hóspede; requerente do serviço doméstico), que usufrui do serviço. Neste trabalho, pretendemos investigar o quanto uma mudança de contexto, de uma situação paga para uma voluntária, de uma aplicação geral para uma voltada a uma comunidade específica, podem alterar as funcionalidades de uma solução e gerar uma maior adesão à ferramenta.

No caso específico de uma aplicação de carona, um grande desafio no seu desenvolvimento é definir as dinâmicas de troca entre os seus usuários. Em [Carroll and Bellotti 2015], os autores analisam as diferentes possibilidades de relações de troca que podem existir em sistemas que intermedeiam serviços pessoa-para-pessoa. Um serviço pessoa-para-pessoa pode ser feito a partir de pagamento em dinheiro, mas também pode ser feito de forma voluntária, ou banco de horas, ou novas moedas, como o Bitcoin [Nakamoto 2008]. Para cada paradigma, há diferentes dinâmicas de troca e implicações para o design da aplicação. Considerações realizadas em sistemas de transporte pago, como no caso do Uber, nem sempre serão as mesmas para sistemas de caronas, em que há um caráter voluntário. O mesmo vale para projetos que têm em vista comunidades específicas, como é o caso de uma comunidade universitária. Como apontado por [Carroll and Bellotti 2015], as dinâmicas de troca podem variar drasticamente com o contexto.

Assim, neste artigo, discutiremos essas relações de troca, segurança e recompensa a partir de considerações feitas durante o processo de desenvolvimento de um aplicativo de caronas para uma universidade, neste caso, na Universidade Federal de Minas Gerais (UFMG). Para isso, apresentamos o que já foi discutido por alguns trabalhos na literatura (Seção 2); a motivação dos usuários a partir de um questionário (Seção 3); as decisões de design durante o desenvolvimento de um protótipo funcional, com base nessas duas etapas anteriores (Seção 4); uma síntese dessas considerações (Seção 5) e concluímos também divulgando uma versão da aplicação na universidade (Seção 6).

\section{Trabalhos Relacionados}

Nesta seção apresentamos os trabalhos relacionados à nossa pesquisa organizados em dois temas de interesse: coprodução e outras aplicações de carona.

\subsection{Coprodução e relações de troca, segurança e recompensa}

Em sistemas de colaboração pessoa-para-pessoa em que não é visada a troca direta de dinheiro ou de bens entre os usuários, novas relações devem ser investigadas. O que motiva um usuário a ofertar determinado serviço? O que ele ganha em troca? Quais as garantias para o demandante que o serviço do ofertante é mesmo seguro? No caso de um aplicativo de caronas, quais as reais vantagens de um motorista em usar determinado aplicativo?

Em [Mauss 1974], o antropólogo Marcel Mauss discute as relações de troca nas sociedades arcaicas. É um dos estudos antropológicos mais importantes sobre reciprocidade e relações de contrato, publicado pela primeira vez em 1924. Em uma série de estudos etnográficos, o ensaio discute que, ao doar um objeto, o doador acaba criando 
uma obrigação no receptor de devolver o presente em igual valor. As relações de troca, comuns desde sociedades mais arcaicas, acabam moldando nossa sociedade e relações com outros indivíduos.

Em [Rifkin 2000], por sua vez, novas formas de mercado são discutidas. No livro, o autor se aproxima na discussão do que temos hoje conhecido como Economia Colaborativa, em que as novas tecnologias têm cada vez mais eliminado os conceitos de propriedade, e a base das relações tem sido a troca de experiências e de bens. Em todo caso, há sempre troca.

Em busca de novos paradigmas de relações de troca entre usuários, o conceito de coprodução tem sido recentemente explorado na literatura de sistemas colaborativos [Carroll 2013]. Nesses casos, ofertante e demandante compartilham ao mesmo tempo de benefícios na execução de um serviço. O conceito de coprodução originou-se na observação de que a efetiva prestação de serviços sociais às vezes depende da participação ativa de quem recebe esses serviços. [Ostrom 1996] ilustra o exemplo dos crimes nas ruas de Chicago. Segundo suas análises, o crime aumenta quando os policiais fazem a vigia no interior das viaturas, evitando o contato direto com as pessoas das ruas. O policial na rua (ofertante) está em uma posição melhor para coproduzir a segurança pública com a participação ativa das pessoas na própria rua (demandante): a polícia e os moradores passam a se conhecer melhor e assim confiam mais uns nos outros, compartilhando fatos e opiniões que ajudam a entender e solucionar direta ou indiretamente os crimes.

Coprodução não é uma cooperação passiva e é mais do que uma simples participação da comunidade no planejamento de uma ação, mas sim uma ação conjunta, em que todos os envolvidos são beneficiados. Um exemplo institucional é o Habitat for Humanity, uma ONG internacional em que a construção de casas é feita através de trabalho voluntário, em que os próprios futuros moradores são mão-de-obra para este trabalho, além daqueles que já receberam auxílio [Carroll 2013].

Tendo em vista esses conceitos, este trabalho pretende investigar as seguintes questões durante o desenvolvimento de um aplicativo de caronas para uma universidade: (1) Existe possibilidade efetiva de coprodução para o contexto investigado (carona, ambiente acadêmico, comunidade fechada)?; (2) Quais as motivações do motorista ao ofertar uma carona, em uma universidade, o que ele espera em troca?; (3) Existem recompensas, além da relação de coprodução, que podem ser consideradas em um aplicativo de carona em uma universidade? Quais?; (4) Quais as preocupações de segurança do motorista (a quais caroneiros ofertar, quais informações prefere conhecer)? e (5) Quais as preocupações de segurança do caroneiro?

\subsection{Aplicações de carona em outras universidades}

Na própria literatura de sistemas colaborativos no Brasil, alguns processos de desenvolvimento de aplicações de carona já foram discutidos. Em [Vieira et al. 2012], a partir de um questionário divulgado em redes sociais, não direcionado especificamente a uma comunidade, os autores discutiram as motivações de possíveis usuários com relação aos aplicativos de caronas. A partir dos resultados do questionário, eles identificaram que as pessoas estão mais aptas a compartilhar caronas com pessoas mais próximas (amigos e parentes: $90 \%$ ) e de grupos específicos (mesma empresa, mesma faculdade (80\%), mesmo curso (61\%)) do que para desconhecidos $(6 \%)$ ou para pessoas que conhecem 
apenas no meio on-line (20\%). Para amigos de amigos ou vizinhos, a taxa também é alta, de 55\%. Esses dados reforçam a importância da delimitação do uso do aplicativo de caronas desenvolvido a comunidades, uma vez que as pessoas se sentem mais confortáveis em compartilhar bens e serviços com outras que são, de alguma forma, próximas.

Além disso, os autores também investigaram as relações entre os tipos de recompensas e a motivação dos usuários para compartilhar caronas. A maior parte das respostas (47\%) foi para a opção "descontos em serviços", porém, por sua vez, a opção "nenhuma recompensa me motivaria" foi a segunda mais marcada, com 34\%. Esse alto índice para a segunda opção pode ter duas explicações: (1) as pessoas não se sentem realmente motivadas de nenhuma forma a usar aplicações de carona, por questões de confiança ou de preferência; ou (2) os usuários poderiam ter outros tipos de motivações para o uso, não buscando necessariamente recompensas diretas e físicas. É com o propósito de investigar as possibilidades da opção 2 que partimos para uma abordagem de questionário direcionada aos alunos da UFMG, conforme discutido na próxima seção. Afinal, quais outras motivações os alunos de uma universidade poderiam ter para usar aplicações de carona, se não puderem receber uma recompensa financeira em troca?

Por fim, em [Macedo et al. 2015] é realizada uma investigação qualitativa com estudantes de uma universidade, que são questionados sobre uma aplicação de caronas para o ambiente acadêmico. A partir de entrevistas com estudantes, os autores chegaram às seguintes considerações, que levamos em conta durante a proposta da aplicação aqui discutida: (1) reputação no sistema e matrícula na universidade são vista com bons olhos para atrair confiança de desconhecidos; (2) motoristas não foram receptivos à ideia de serem mal avaliados por um caroneiro, devido ao caráter voluntário da carona; (3) caroneiros e motoristas preferem, quando houver, avaliações anônimas; (4) participantes preferem não assumir compromissos a longo prazo, na hora de agendar caronas, uma vez que podem haver imprevistos; (5) motoristas e caroneiros não se sentiram à vontade com a ideia de pagamentos, sendo vistos como uma descaracterização do favor; e (6) mulheres se mostram mais vulneráveis na questão de segurança. Todas essas considerações são discutidas nesse artigo em tempo de projeto, na Seção 4, que descreve as decisões tomadas relativas a esses pontos.

\section{Questionário on-line: Considerações do contexto da comunidade}

Embora pesquisas tenham sido e estejam sendo realizadas em outras universidades brasileiras investigando e desenvolvendo aplicativos de carona (conforme exemplificado na Seção 2.2), decidimos aqui realizar uma investigação direcionada ao ambiente da nossa própria universidade, a Universidade Federal de Minas Gerais (UFMG), durante a fase de desenvolvimento de um novo aplicativo (decisões de projeto estão apresentadas em detalhes na Seção 4). Nesse caso, realizamos um questionário e o distribuímos a membros da comunidade acadêmica, cujos resultados serviram como material para dois direcionamentos: (1) entender as particularidades desta comunidade no qual uma nova aplicação está sendo desenvolvida e que não teriam como ser levantadas em pesquisas anteriores em outras universidades; e (2) investigar a influência de uma comunidade - no caso, a acadêmica - em uma aplicação - no caso, um aplicativo de caronas para dispositivos móveis. Nessa seção, apresentamos os resultados relacionados aos dois direcionamentos, mas mantendo como foco a discussão dos fatores de 1 que influenciam em 2. Ou seja, queremos aqui apresentar o quanto as considerações de uma comunidade podem alterar 
ou não as decisões de projeto de uma aplicação, tendo a nossa universidade como estudo de caso.

O questionário teve sua distribuição de forma on-line (a partir do Google Forms ${ }^{4}$ ) e abordou questões relacionadas aos seguintes temas: uso ou não uso de carro para se locomover na universidade, rotina e motivos; informações sobre caronas ofertadas dentro do campus; informações sobre caronas solicitadas; motivos para dar ou pegar caronas, ou motivos para não dar ou pegar caronas; e uso de aplicações móveis. O questionário foi divulgado entre os meses de dezembro e março de 2016, sendo respondido por 290 pessoas, tendo 287 respostas válidas ( 3 pessoas não eram membros da UFMG, o questionário possuía uma pergunta que evitava a participação nesses casos).

O questionário foi divulgado em grupos de discussão no Facebook ${ }^{5}$. Na rede social em questão, é possível encontrar grupos direcionados a comunidades e diferentes assuntos dentro dessas comunidades, como é o caso de grupos específicos de alunos da UFMG e grupos direcionados a caronas dentro da própria universidade. No caso, realizamos a divulgação do questionário nos seguintes grupos (em um total de 20): (1) grupos direcionados a caronas dentro da UFMG - nesses grupos, encontraríamos membros que já estão dispostos e abertos à ideia de caronas na universidade (4 grupos; o maior com 6.000 membros e média de 2.500, em março de 2016); (2) grupos que levam o nome da universidade - a fim de divulgar o questionário a um maior número de pessoas ( 3 grupos; o maior com 14.000 membros e os outros dois com média de 3.000, em março de 2016); e (3) grupos direcionados a diferentes cursos dentro da universidade - com o propósito de obter um conjunto mais heterogêneo de participantes (13 grupos, o maior com 5.000 membros, média de 2.000).

Em relação ao perfil atingido pelo questionário a partir da estratégia de divulgação adotada, $78 \%$ foram alunos de graduação, $15,6 \%$ alunos de pós-graduação e os demais $6 \%$ funcionários ou alunos de cursos técnicos. Sobre a faixa etária, 59,9\% têm entre 18 e 23 anos, $31 \%$ estão entre 23 e 28 anos, $8,1 \%$ os demais (7,1\% acima de 28 anos e $1 \%$ abaixo de 18). Quanto ao gênero, 51,6\% marcaram feminino, 47,4\% masculino e 1\% preferiu não informar.

Divulgar o questionário nesses grupos fez com que o perfil dos participantes fosse de pessoas mais propensas a oferecer caronas naturalmente e pessoas que, de certa forma, estão interessadas em se entrosar com o público da própria universidade. Dentre os participantes, 108 disseram que vão de carro para a universidade (38\% do total), 84 responderam que dão ou já deram carona para alguém dentro do campus. Ou seja, 78\% dos motoristas interessados em participar da pesquisa estão abertos à ideia de oferecer caronas. De todos os 287 participantes da pesquisa, 185 (64\%) já pegaram carona em algum momento. Dentre os participantes que afirmaram não ter carro ou não ir regularmente de carro para o campus, 68\% disseram já ter pego carona. Ou seja, a maioria das pessoas que se sentiram motivadas a preencher o questionário on-line se interessam em oferecer caronas ( $78 \%$ dos motoristas) ou demonstram interesse em pegar caronas (64\% dos não

\footnotetext{
${ }^{4}$ https://www.google.com/forms/about/, último acesso em maio de 2016.

${ }^{5}$ Segundo dados de 2014, o Facebook é acessado por $45 \%$ dos brasileiros (conforme divulgado em https://www.facebook.com/business/news/ BR-45-da-populacao-brasileira-acessa-o-Facebook-pelo-menos-uma-vez-ao-mes, último acesso em maio de 2016).
} 
motoristas).

Devido ao direcionamento gerado pela divulgação do questionário e à limitação de alcance via rede social, os números aqui apresentados não constituem uma amostra representativa dos estudantes da universidade como um todo. A UFMG possui atualmente mais de 33 mil alunos de graduação, 14 mil de pós e 1,6 mil de educação profissionalizante $^{6}$. Assim, os participantes do questionário representam apenas $0.6 \%$ dos alunos da UFMG, sem levar em consideração professores e funcionários. Ainda assim, este greupo é de interesse uma vez que representam o perfil dos potenciais usuários a quem o aplicativo se destina, isto é: motoristas e não motoristas interessados no assunto e participantes de redes sociais. A seguir, apresentamos os principais tópicos obtidos a partir da análise do questionário.

Propensão para caronas dentro da universidade: Dentre os participantes que vão regularmente de carro para a universidade (81 pessoas, $28 \%$ do total de participantes; excluindo aqueles que vão apenas algumas vezes), 81,5\% informaram que já deram ou costumam dar caronas para pessoas dentro do próprio campus. Quando questionados sobre a frequência dessas caronas oferecidas, a maioria desses motoristas ou dão caronas na maior parte da semana ou pelo menos uma vez por semana (60\% marcou pelo menos uma vez por semana ou mais) ou então dão caronas muito esporadicamente (40\% marcou que dá carona pelo menos algumas vezes ao mês ou menos). Ou seja, já existe um movimento por parte de alguns alunos motoristas para a oferta de caronas dentro do campus. E para aqueles que ofertam, essa oferta pode ser frequente e contínua.

Ambiente acadêmico como fator de confiança para oferecer caronas: Foram apresentados aos participantes cinco cenários nos quais eles deveriam responder, em uma escala Likert de 1 (discordo fortemente) a 5 (concordo fortemente), a propensão para oferecer caronas para cada uma das situações apresentadas. Os cenários variavam de situações de maior exposição (cenário 1: dar caronas a desconhecidos em qualquer lugar na cidade) a situações muito restritas ao ambiente acadêmico (cenário 5: dar caronas a conhecidos dentro do campus da universidade). Os cenários estão ilustrados na Figura 1.

A Figura 1 sugere que a disposição para dar caronas aumenta à medida em que o motorista conhece o caroneiro e se encontra em um local de confiança, também já conhecido, como é o caso do campus de uma universidade (confiança em pessoa conhecida $>$ pessoa desconhecida, porém sabe que é membro da universidade $>$ pessoa desconhecida, porém está no ambiente do campus $>$ pessoa desconhecida, fora do campus). O uso de um aplicativo de caronas, por sua vez, melhora um pouco a confiança: o cenário 2 apresenta resultados melhores que o cenário 1 . No entanto, o cenário 2 não possui confiança maior que os cenários 3, 4 e 5, em que o caroneiro se encontra no ambiente físico do campus. Tanto no cenário 2 quanto no 3 o número de pessoas que discorda da afirmativa (em vermelho na Figura 1), que não daria carona, é de 20 pessoas (23,8\%). Porém, no cenário 3 mais pessoas estariam dispostas a dar caronas que no 2 - em azul, 53 pessoas $(63,1 \%)$ contra 43 pessoas $(51,1 \%)$. No cenário 4 , em que o vínculo com a comunidade acadêmica é garantido, a disposição para a carona aumenta mais (61 pessoas, 70,6\%), ainda que a pessoa seja desconhecida.

\footnotetext{
${ }^{6}$ Segundo levantamento realizado pela UFMG em novembro de 2015 (https : / / www . ufmg .br/ conheca/nu_index.shtml, último acesso em maio de 2016).
} 

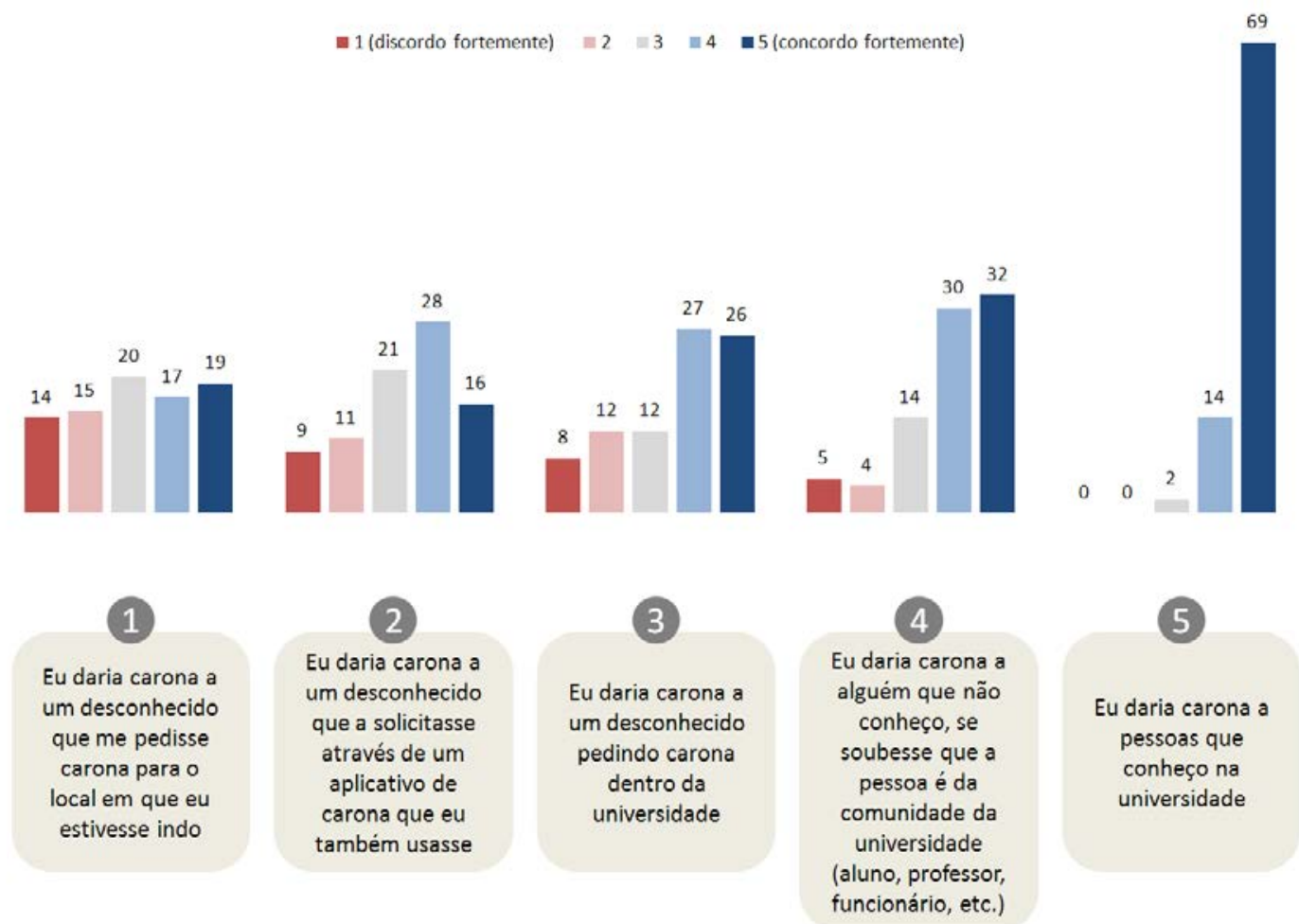

Figura 1. Escala Likert para cenários em situações de carona dentro da universidade: motoristas estão mais dispostos a dar caronas para pessoas de dentro da universidade e conhecidos (cenário 5) do que para desconhecidos em ambientes fora da universidade (cenário 1).

Preocupações com segurança: Das 102 pessoas que afirmaram não pegar caronas, quando questionadas sobre os motivos para isso, 39 marcaram que tinham medo de sofrer alguma violência (38\%). Dessas, 33 são mulheres (85\%), enquanto apenas 5 são homens (uma pessoa não quis informar o seu gênero). Essa informação reforça o que já foi sugerido de forma qualitativa no trabalho [Macedo et al. 2015], sobre uma preocupação maior por parte das mulheres com a segurança nesse tipo de aplicação. Já das 108 pessoas que informaram que vão de carro para o campus (38\% de todos os participantes), 24 disseram nunca ter dado carona a alguém dentro do campus (22\% dos motoristas). Dessas 24 pessoas, quando questionadas sobre os motivos para não dar caronas, 12 pessoas $(50 \%)$ responderam ter medo de sofrer qualquer tipo de violência, e o número entre homens e mulheres nesse caso ficou equilibrado ( 7 mulheres e 5 homens).

Recompensas através de uma aplicação: Um grande desafio no projeto de sistemas colaborativos de carona é oferecer recompensas para o motorista. Por ser de caráter voluntário, é esperado que tais sistemas sejam mais vantajosos para o caroneiro do que para o motorista, já que este pode não ter muito a ganhar em troca, ao contrário do caroneiro, que ganha a viagem. Assim, investigamos quais as possíveis motivações dos participantes, em especial dos motoristas. Essa investigação foi feita com os participantes que responderam possuir carro e ir regularmente com ele para a universidade $(\mathrm{n}=81)$. Os resultados são apresentados na Figura 2.

A recompensa de ajudar um amigo ou conhecido foi a mais votada, sendo marcada por 90,1\% dos motoristas. As recompensas de melhorar o trânsito na cidade e contribuir para 


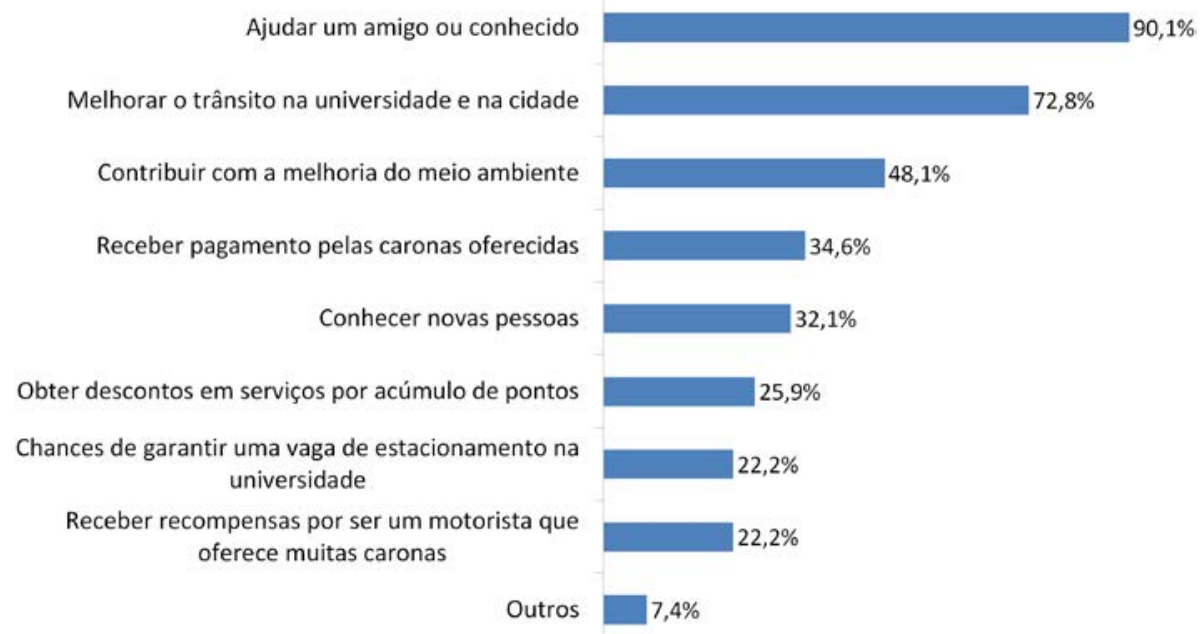

Figura 2. Respostas para a pergunta do questionário "Considerando o uso de um aplicativo de carona para celular, quais das motivações são mais relevantes para você considerar dar carona a alguém?"; essa pergunta foi respondida por 81 motoristas, que podiam marcar mais de uma questão.

o meio ambiente foram a segunda e terceira recompensas mais citadas, respectivamente. A recompensa material mais bem colocada, que consiste em receber um pagamento pelas caronas oferecidas, ficou em quarto lugar, sendo considerada uma motivação relevante por $34.6 \%$ dos participantes.

Para aplicações voltadas a comunidades, as recompensas também podem ser de valor local ou mesmo valor social, e não necessariamente valores financeiros. Das respostas apresentadas na Figura 2, a grande maioria dos motoristas tem hoje como principais motivações as recompensas de valor social. No caso da UFMG, uma necessidade que investigamos com os participantes do questionário para uma possível recompensa de valor local foi a questão de estacionamento no campus. Embora "chances de garantir uma vaga de estacionamento" tenha sido a penúltima opção indicada como motivação para usar um aplicativo, parte dos motoristas relataram alguma dificuldade para encontrar vagas de estacionamento no campus. Dos motoristas, $44 \%$ relatou dificuldade razoável e $35 \%$ difícil ou muito difícil. Pelos dados do questionário, as recompensas de valor social inicialmente são mais previlegiadas por parte dos motoristas da comunidade em questão do que as recompensas de valor local que inicialmente propomos.

\section{Carona UFMG: Aplicação móvel e decisões de projeto}

Nesta seção discutimos as principais funcionalidades implementadas no aplicativo (app) e as decisões de projeto adotadas. As telas iniciais do aplicativo (login, menu com principais funcionalidades e tela de perfil) estão ilustradas na Figura 4.

Principais funcionalidades: Na aplicação aqui desenvolvida, os motoristas podem divulgar suas rotas com pontos de partida, intermediários e de chegada, além de data e horário (Figura 4.a). Esses roteiros podem ser vistos por outros usuários que estão procurando por transporte, os caroneiros (Figura 4.c). Uma vez identificada uma rota, o caroneiro faz a requisição de carona para o motorista que publicou a rota, que pode ou não aceitar a solicitação. $\mathrm{O}$ aplicativo também permite que usuários que não possuem carro divulguem 


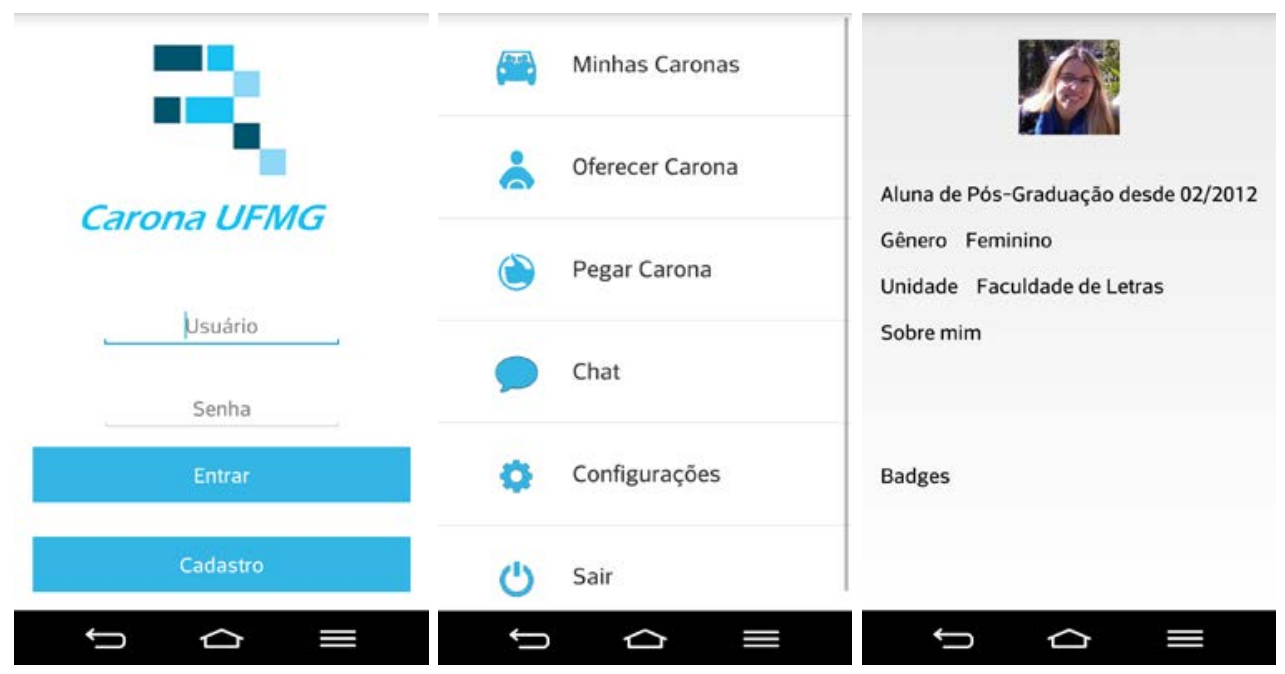

Figura 3. (a) Tela inicial de login (e-mail institucional é exigido); (b) menu de opções do app e (c) tela de perfil de um usuário.

os seus trajetos. Um motorista, ao identificar um trajeto similar ao seu, pode oferecer carona a alguém que precise, ficando a cargo do caroneiro aceitar ou não a carona (Figura 4.b). O aplicativo também conta com um sistema de bate-papo, por meio do qual eles podem acertar os detalhes da carona, como combinar o ponto de encontro ideal ou avisar previamente sobre atrasos, por exemplo. Além disso, foi desenvolvido um processo de autenticação para garantir que o usuário é membro da comunidade da UFMG, a fim de aumentar a segurança dentro da rede de caroneiros e a confiança dos usuários ao utilizarem o sistema. Também foi proposto um sistema de reputação, que permite que cada usuário seja avaliado com base em notas dadas por outros usuários e que, quando combinadas, formam uma métrica da reputação do usuário dentro da rede de compartilhamento de caronas. Essa reputação pode ser vista por outros usuários e utilizada como subsídio no momento de decidir se dará ou não carona para o referido usuário. Usuários com a reputação muito abaixo da média também podem ser banidos do sistema, com o intuito de manter a qualidade dos participantes da rede.

Aplicação Android: Uma vez que estamos propondo um sistema colaborativo, a adesão dos usuários é determinante para o sucesso do mesmo. Quanto mais usuários aderirem ao sistema, maior será o número de rotas disponíveis e de pessoas procurando por carona, aumentando, assim, o número de caronas agendadas [Teal 1987][Kaufman 2002]. Para a implementação de uma primeira versão do aplicativo, foi escolhida a plataforma Android, marcada como sendo utilizada por $73,2 \%$ das pessoas que preencheram o questionário, podendo ter mais chances, portanto, de adesão.

Arquitetura: O sistema proposto é baseado no modelo cliente-servidor. O objetivo desta divisão é separar a arquitetura e responsabilidades em dois ambientes. Foi implementado um WebService com o propósito de receber as requisições e intermediar as interações entre os usuários do aplicativo, cumprindo, assim, o papel de servidor. Este WebService foi baseado no modelo REST - Representational State Transfer, que possui as características de ser stateless, cacheable e ter uma interface uniforme. Essa arquitetura permite que a base de dados de caronas possa ser consumida por outros sistemas, facilitando o surgimento de novas soluções que possam tirar proveito desses dados. 

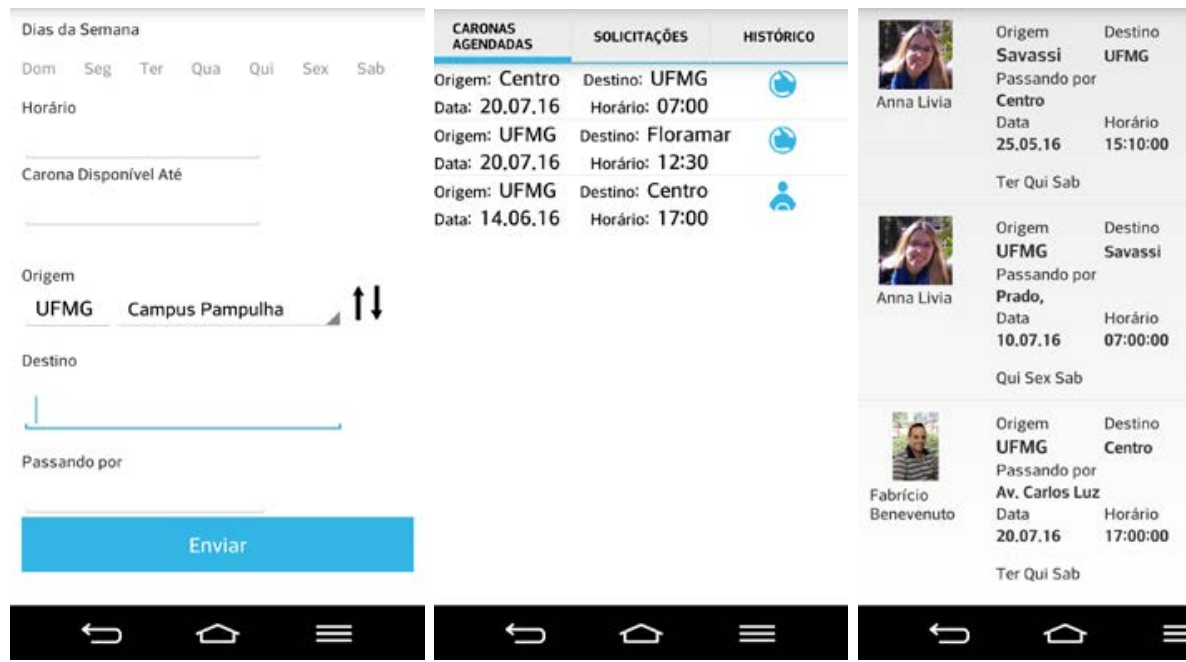

$\hookrightarrow$

口

$\equiv$

$\triangle$

Figura 4. (a) Tela para o motorista cadastrar uma carona; (b) Tela de caronas agendadas, cadastradas tanto por caroneiros, quanto por motoristas e (c) Lista de opções de caronas para serem requeridas, em que é possível visualizar a foto de perfil e outras informações do usuário.

Autenticação: A solução proposta consiste na utilização do e-mail institucional da universidade no processo de cadastro de usuários. Sempre que um usuário se inscreve no sistema de caronas, ele é requisitado a informar, obrigatoriamente, um e-mail do domínio da universidade. O sistema, em seguida, envia para o endereço de e-mail informado um link único que deve ser acessado pelo usuário a fim de validar o e-mail utilizado no momento do cadastro. Enquanto não é feito esse processo de validação, a conta do usuário permanece inativa e o usuário não consegue fazer login no app. O que garante que apenas membros da comunidade acadêmica consigam acessar o sistema.

Cadastro de Rotas: Como o sistema de caronas tem o intuito de atender apenas à comunidade universitária, o aplicativo só permite o cadastro de rotas que tenham a UFMG como ponto inicial ou final. O aplicativo também oferece uma listagem dos prédios da instituição. O sistema só permite que os pontos de origem e destino escolhidos fora do campus da universidade sejam indicados a partir de uma listagem pré-definida de bairros das cidades da Região Metropolitana de Belo Horizonte. Isso faz com que não seja possível que endereços específicos sejam incluídos no sistema e fiquem disponíveis para todos os outros usuários, a fim de manter a privacidade dos mesmos. Uma vez solicitada uma carona, o caroneiro e o motorista podem utilizar o bate-papo a fim de combinarem os locais específicos de início e fim da carona.

Caronas totais $\mathbf{x}$ caronas parciais: Para que uma carona possa ser combinada com sucesso, não é necessário que os dois passageiros tenham a mesma origem e o mesmo destino. Um pessoa pode, por exemplo, passar pelo bairro de outra a caminho da sua própria casa. Nesse caso é possível que seja dada uma carona parcial, na qual o caroneiro não acompanha o motorista por todo o seu trajeto. Por esse motivo, o aplicativo permite que, ao cadastrar uma rota, o usuário também cadastre pontos intermediários pelos quais passa no seu trajeto de/para a universidade.

Caronas únicas $\mathbf{x}$ Caronas recorrentes: Um dado motorista pode percorrer uma rota uma única vez ou então percorrê-la com certa periodicidade. Da mesma forma, uma 
pessoa que procura por caronas pode precisar percorrer o trajeto uma única vez ou com certa frequência. Por esse razão, as rotas podem ser cadastradas pelo usuário como únicas ou recorrentes. As caronas únicas possuem datas definidas e são exibidas no sistema do momento do seu cadastro até a data da carona. Já as recorrentes são exibidas desde sua inclusão no sistema até uma data final escolhida pelo usuário no momento do cadastro.

Informações de perfil: $\mathrm{O}$ perfil de cada pessoa apresenta dados pessoais tais como nome, foto, data de ingresso e vínculo com a universidade. As informações apresentadas são preenchidas pelo próprio usuário no momento do cadastro no sistema. Também é disponibilizado um campo que pode ser preenchido com texto livre.

Reputação: Após uma carona, a pessoa que ofereceu carona pode avaliar, com uma nota de 1 a 5 estrelas, o passageiro e vice-versa. A partir dessas avaliações, cada usuário do sistema terá a sua própria nota de reputação, calculada levando em conta as suas avaliações. A literatura mostra que os usuários desse tipo de sistema têm aversão à ideia de ter avaliações negativas publicadas. Essa aversão é ainda maior quando se trata dos motoristas uma vez que estes veem o ato de oferecerem carona como um favor. $\mathrm{Na}$ literatura também é citado que as avaliações devem ser, preferencialmente, anônimas [Macedo et al. 2015]. Por esse motivo, propomos um sistema de reputação que pretende utilizar as avaliações de forma anônima para o cálculo das reputações e ao mesmo tempo preservar os usuários com notas ruins. A solução proposta na aplicação faz uso, portanto, do conceito de gamefication chamado de badges ou conquistas para identificar os usuários que se destacam de maneira positiva em relação aos outros. Um usuário ganha uma badge sempre que este conseguir completar uma realização notável dentro do sistema. Essas conquistas são apresentadas nos perfis de cada usuário que as conquistou e servem de subsídios para outros usuários decidirem se devem ou não dar caronas. Esse recurso também serve como forma de incentivo para os usuários, que podem se sentir reconhecidos ao recebê-las e motivados a conquistar outras [Grant and Betts 2013]. Dessa forma, os usuários nunca têm acesso diretamente às notas que receberam em suas avaliações, mas conseguem ter um feedback do seu desempenho por meio das badges. Já os usuários que se destacarem negativamente dentro do sistema, acumulando avaliações ruins, nunca serão expostos mas podem ser banidos do sistema por parte dos administradores, o que objetiva manter certo nível de qualidade dos usuários da plataforma.

Bate-papo: O sistema também conta com um serviço de bate-papo para que motoristas e passageiros possam conversar livremente. Este foi criado para permitir que os usuários possam combinar de forma detalhada a carona, como escolher um ponto de encontro exato ou avisar sobre um possível atraso. Os usuários também podem usar o bate-papo para a troca de informações pessoais como telefones e endereços. O bate-papo conta, ainda, com uma funcionalidade que permite que um usuário abra o mapa da cidade, marque um ponto e envie para o destinatário, que por sua vez consegue abrir o mapa e ver qual ponto foi marcado pelo remetente. $\mathrm{O}$ bate-papo entre dois usuários só é possível depois que um tiver enviado uma solicitação de carona para o outro. Uma vez que a carona foi dada, esse meio de comunicação entre eles deixa de existir. 


\begin{tabular}{|c|c|c|}
\hline & Carona UFMG & $\begin{array}{l}\text { Outros apps tradicionais de carona } \\
\text { (fora do contexto de uma comuni- } \\
\text { dade; exs.: BlaBlaCar, Zumpy) }\end{array}$ \\
\hline Autenticação & $\begin{array}{l}\text { É feita via e-mail institucional; so- } \\
\text { mente membros da comunidade } \\
\text { acadêmica tem acesso. Evita o } \\
\text { surgimento de usuários fakes. }\end{array}$ & $\begin{array}{l}\text { Feita por meio de cadastro próprio ou } \\
\text { por meio de logins via redes sociais; } \\
\text { aberta a qualquer usuário }\end{array}$ \\
\hline Banco de Dados & $\begin{array}{l}\text { É armazenado e fica disponível para o } \\
\text { uso da própria instituição; os dados po- } \\
\text { dem ser utilizados para entender e me- } \\
\text { lhorar a mobilidade na instituição }\end{array}$ & $\begin{array}{l}\text { É armazenado por uma empresa e so- } \\
\text { mente esta tem acesso às informações }\end{array}$ \\
\hline Integração & $\begin{array}{l}\text { Permite a integração com outros siste- } \\
\text { mas da instituição }\end{array}$ & $\begin{array}{l}\text { Pode ter integração com outras empre- } \\
\text { sas (como Facebook e convênios com } \\
\text { demais empresas) }\end{array}$ \\
\hline Customização & $\begin{array}{l}\text { Customizável para cada instituição; } \\
\text { é possível realizar a alteração das } \\
\text { informações contidas no perfil, nome } \\
\text { das unidades e domínios dos e-mails } \\
\text { utilizados para a autenticação, entre ou- } \\
\text { tros }\end{array}$ & $\begin{array}{l}\text { Não são customizáveis, domínio de } \\
\text { uma empresa }\end{array}$ \\
\hline Recompensas & $\begin{array}{l}\text { A fim de aumentar a adesão ao sistema, } \\
\text { permite a utilização de recompensas lo- } \\
\text { cais (como vagas na universidade) }\end{array}$ & $\begin{array}{l}\text { Recompensas como desconto em gaso- } \\
\text { linas, ingressos de cinema, etc.; recom- } \\
\text { pensas financeiras }\end{array}$ \\
\hline
\end{tabular}

\section{Decisões de Projeto: Motivações e Contrastes}

Das funcionalidades da aplicação apresentadas na seção anterior, muitas se diferem das aplicações tradicionais de caronas (como a BlaBlaCar ${ }^{7}$ e o Zumpy ${ }^{8}$ ), que são abertas a qualquer público. Na Tabela 1, apresentamos as principais diferenças ao se comparar esses tipos de aplicativos com o aqui apresentado, direcionado a uma comunidade. Essa tabela pretende ressaltar algumas das vantagens que podem surgir ao se ter uma aplicação direcionada a um contexto e as decisões de projeto aqui definidas.

Em relação ao que foi discutido nas seções anteriores, resumimos nas Tabelas 2 e 3 os principais resultados, com o propósito de fazer uma breve apresentação do que foi considerado no projeto da aplicação e ressaltar pontos importantes a serem considerados em aplicações voltadas a comunidades.

\section{Considerações Finais}

Nesse artigo, apresentamos o processo de desenvolvimento de um sistema para o compartilhamento de caronas dentro de uma comunidade acadêmica. Uma pesquisa exploratória foi realizada a fim de identificar o estado atual da utilização de caronas na UFMG. Foi identificada a existência de uma cultura de compartilhamento de caronas e um potencial de expansão da utilização destas pelos membros da comunidade. A preocupação com a segurança pessoal e a dificuldade em encontrar outras pessoas que façam o mesmo trajeto foram citadas como as principais barreiras para que ocorra essa expansão. $\mathrm{O}$ artigo

\footnotetext{
${ }^{7}$ https: / / www.blablacar.com.br/

${ }^{8}$ http: / / www. zumpy.com.br/
} 
Tabela 2. Considerações sobre aplicações de carona encontradas em outras publicações no SBSC e levantadas no questionário on-line aqui aplicado com membros da comunidade acadêmica

\begin{tabular}{|c|c|c|}
\hline Considerações & Fonte & Impacto na especificação do sistema \\
\hline $\begin{array}{l}\text { Coprodução: em uma aplicação se- } \\
\text { melhante a aplicações de economia } \\
\text { colaborativa, porém voltadas a co- } \\
\text { munidades e de caráter voluntário, } \\
\text { o conceito de coprodução pode ser } \\
\text { interessante de ser explorado (no } \\
\text { caso de caronas: encontrar formas } \\
\text { para que motoristas e caroneiros se- } \\
\text { jam mútua e instantaneamente be- } \\
\text { neficiados) }\end{array}$ & $\begin{array}{l}\text { Conceito de } \\
\text { coprodução } \\
\text { explorado } \\
\text { em [Carroll, } \\
2013]\end{array}$ & $\begin{array}{l}\text { Motoristas ganham conquistas (badges) podendo } \\
\text { ganhar vantagens e vagas na universidade, ca- } \\
\text { roneiros ganham a carona. Coprodução não } \\
\text { está sendo diretamente considerada, ambos não } \\
\text { ganham vantagens instantaneamente, porém ao } \\
\text { longo de um tempo. Pelo questionário, recompen- } \\
\text { sas de valor social são as mais importantes, por- } \\
\text { tanto pode haver coprodução nesse sentido: moto- } \\
\text { rista ganha a companhia de um amigo, no caso, o } \\
\text { caroneiro. }\end{array}$ \\
\hline $\begin{array}{l}\text { Usuários estão propensos a intera- } \\
\text { gir com pessoas conhecidas mais do } \\
\text { que desconhecidas }\end{array}$ & $\begin{array}{l}\text { [Vieira et al., } \\
\text { 2012]; Ques- } \\
\text { tionário }\end{array}$ & $\begin{array}{l}\text { No caso, a aplicação ainda não prioriza automati- } \\
\text { camente conhecidos de desconhecidos, ou amigos } \\
\text { próximos. }\end{array}$ \\
\hline $\begin{array}{l}\text { Usuários se sentem mais seguros } \\
\text { em comunidades e com as pessoas } \\
\text { dessas comunidades locais }\end{array}$ & $\begin{array}{l}\text { [Macedo et } \\
\text { al., 2015]; } \\
\text { Questionário }\end{array}$ & $\begin{array}{l}\text { A aplicação exige e-mail institucional no processo } \\
\text { de cadastro. O que garante que apenas membros } \\
\text { da universidade tenham acesso ao sistema. Isso } \\
\text { também evita o surgimento de usuários fakes. }\end{array}$ \\
\hline $\begin{array}{l}\text { Recompensa social, em uma comu- } \\
\text { nidade, pode ser mais bem vista do } \\
\text { que qualquer outra }\end{array}$ & Questionário & $\begin{array}{l}\text { O próprio uso de um aplicativo voltado a uma co- } \\
\text { munidade específica viabiliza essa consideração. } \\
\text { Ranking de top usuários também promove esse re- } \\
\text { conhecimento. Esse ranking já pode ser feito a } \\
\text { partir do banco de dados do aplicativo e é a partir } \\
\text { deste que espera-se distribuir as vagas reservadas. }\end{array}$ \\
\hline $\begin{array}{l}\text { Recompensa local também pode ser } \\
\text { um atrativo a ser considerado }\end{array}$ & $\begin{array}{l}\text { [Vieira et al., } \\
\text { 2012]; Ques- } \\
\text { tionário }\end{array}$ & $\begin{array}{l}\text { A partir do engajamento de cada usuário no sis- } \\
\text { tema e das avaliações feitas por estes depois de } \\
\text { cada carona, é gerado um ranking de usuários. } \\
\text { Esse ranking pode ser utilizado para dar recom- } \\
\text { pensas aos usuários mais bem classificados. No } \\
\text { caso específico da UFMG, propomos que algumas } \\
\text { vagas de estacionamento sejam reservadas a estes } \\
\text { motoristas. }\end{array}$ \\
\hline $\begin{array}{l}\text { Motoristas não gostam de ser mal } \\
\text { avaliados, pois veem a oferta de ca- } \\
\text { rona como um favor sendo feito }\end{array}$ & $\begin{array}{l}\text { [Macedo et } \\
\text { al., 2015] }\end{array}$ & $\begin{array}{l}\text { Apesar de o sistema permitir que os usuários se- } \\
\text { jam avaliados entre si, as notas não são exibi- } \\
\text { das na aplicação. Essas avaliações são refletidas } \\
\text { no aplicativo por meio de conquistas (badges). } \\
\text { Sempre que um usuário conseguir um determi- } \\
\text { nado número de notas máximas nas avaliações, } \\
\text { por exemplo, ganha uma badge. As badges de } \\
\text { um determinado usuário são exibidas em seu per- } \\
\text { fil público, o que serve de subsídio para que outras } \\
\text { pessoas decidam pegar ou dar carona para aquele } \\
\text { usuário. Essas badges só são concedidas para boas } \\
\text { conquistas, reconhecendo e incentivando o bom } \\
\text { comportamento dos usuários e não expondo os } \\
\text { usuários com médias ruins nas avaliações. }\end{array}$ \\
\hline
\end{tabular}


Tabela 3. Considerações sobre aplicações de carona encontradas em outras publicações no SBSC e levantadas no questionário on-line aqui aplicado com membros da comunidade acadêmica (continuação)

\begin{tabular}{|l|l|l|}
\hline Considerações & Fonte & Impacto na especificação do sistema \\
\hline $\begin{array}{l}\text { Preferência para agendamentos de } \\
\text { caronas em prazos curtos }\end{array}$ & $\begin{array}{l}{[\text { Macedo et }} \\
\text { al., 2015] }\end{array}$ & $\begin{array}{l}\text { O sistema lista as caronas disponíveis conside- } \\
\text { rando o prazo restante para o horário da carona. } \\
\text { Caronas para daqui a uma hora são exibidas antes } \\
\text { de caronas para daqui a cinco horas na listagem de } \\
\text { caronas disponíveis, por exemplo. Caronas para } \\
\text { hoje são exibidas antes de caronas para amanhã. }\end{array}$ \\
\hline $\begin{array}{l}\text { Permitir informar horários } \\
\text { contínuos e frequentes }\end{array}$ & Questionário & $\begin{array}{l}\text { Motoristas e caroneiros podem dispor de horários } \\
\text { contínuos (vários horários durante uma semana ou } \\
\text { no mês), sem precisar informar o mesmo horário } \\
\text { sempre. }\end{array}$ \\
\hline
\end{tabular}

também descreveu alguns detalhes da arquitetura do sistema e suas principais funcionalidades. As decisões de projeto foram discutidas e baseadas em trabalhos descritos na literatura e em um questionário realizado com membros da universidade. Embora aqui tenhamos apresentado algumas decisões do desenvolvimento do aplicativo, uma versão já se encontra pronta e disponível para a comunidade acadêmica da UFMG por meio da Google Play, plataforma de distribuição de aplicativos da plataforma Android. O aplicativo pode ser encontrado no link: http://www.carona.dcc.ufmg.br/.

Na discussão sobre o conceito de coprodução e recompensas, em que ambos (motorista e caroneiro) possam ser beneficiados por uma aplicação, identificamos que há possibilidades de benefícios para ambos. Porém, para o motorista os benefícios sociais apresentaram-se mais relevantes do que os financeiros e até mesmo os locais. Pode ser que pela cultura de caronas já existente na universidade, os motoristas estejam mais dispostos a oferecer caronas não visando recompensas, mas sim ajudar os outros membros da comunidade. Novas formas de recompensas locais ainda devem ser discutidas na comunidade, como foi o caso aqui da garantia de vagas de estacionamento, apontadas como alvo, devido a dificuldade de encontrar vagas atualmente no campus.

As preocupações de segurança também foram aqui investigadas e medidas foram tomadas durante o desenvolvimento da aplicação apresentada, como a exigência de um e-mail institucional para o acesso ao sistema e a necessidade parcial de algumas informações, como a foto de perfil, gênero e informações acadêmicas (curso, unidade acadêmica, vínculo com a universidade). Ainda que não obrigatórias (um usuário pode não postar sua foto de perfil, por exemplo), essas informações são fortemente sugeridas pela interface do sistema.

Como próximos passos, pretendemos realizar entrevistas direcionadas a motoristas e caroneiros sobre algumas decisões de projeto discutidas aqui, como a adesão do sistema de badges e avaliação de outros usuários. Também pretendemos realizar um estudo do comportamento dos usuários a partir dos $\log s$ de utilização do sistema e a disponibilização desses $\log s$ anonimizados para a utilização da comunidade científica. Novas funcionalidades serão incluídas na ferramenta como recomendação de caronas baseada nos históricos de utilização de cada usuário e um sistema anti-fraudes, a fim de garantir que apenas os usuários que realmente deram caronas recebam os incentivos ofe- 
recidos aos usuários melhor avaliados pelo sistema.

\section{Agradecimentos}

Agradecemos aos participantes do questionário por sua colaboração; e às agências CNPq, CAPES e FAPEMIG, bem como ao InWeb (MCT/CNPq 573871/2008- 6) e MASWeb (FAPEMIG/PRONEX APQ-01400-14) por seu apoio financeiro parcial a esta pesquisa.

\section{Referências}

Carroll, J. M. (2013). Co-production scenarios for mobile time banking. In End-User Development - 4th International Symposium, IS-EUD 2013, Copenhagen, Denmark, June 10-13, 2013. Proceedings, pages 137-152.

Carroll, J. M. and Bellotti, V. (2015). Creating value together: The emerging design space of peer-to-peer currency and exchange. In Proceedings of the 18th ACM Conference on Computer Supported Cooperative Work \& Social Computing, CSCW '15, pages 1500-1510, New York, NY, USA. ACM.

Grant, S. and Betts, B. (2013). Encouraging user behaviour with achievements: An empirical study. In Proceedings of the 10th Working Conference on Mining Software Repositories), pages 65-68.

Hamari, J., Sjöklint, M., and Ukkonen, A. (2015). The sharing economy: Why people participate in collaborative consumption. American Society for Information Science and Technology. Journal. Epub ahead of print. Published online: 2 June 2015.

Kaufman, S. (2002). Why people (dont) carpool and change for the better: A social capital framework for investigating environmental behaviour. In 2nd National Conference of Sustainable Campuses, RMIT.

Macedo, R. d. F., Gomes, A. L., Andrade, N., and Maia, D. C. (2015). Caronas à brasileira: uma investigação centrada no usuário sobre o projeto de sistemas de caronas em uma universidade brasileira. In Simpósio Brasileiro de Sistemas Colaborativos - SBSC 2015.

Mauss, M. (1974). Ensaio sobre a Dádiva. EPU, São Paulo.

Nakamoto, S. (2008). Bitcoin: A peer-to-peer electronic cash system. http:// bitcoin.org/bitcoin.pdf.

Ostrom, E. (1996). Crossing the great divide: co-production, synergy, and development. World Development, pages 1073-1087.

Rachel Botsman, R. R. (2010). What's mine is yours: the rise of collaborative consumption. HarperCollins Publisher.

Rifkin, J. (2000). The Age of Access: The New Culture of Hypercapitalism Where All of Life Is a Paid-For Experience. Putnam Publishing Group, The.

Teal, R. (1987). Carpooling: Who, how and why. Transportation Research, 21A:203214.

Vieira, V., Fialho, A., Martinez, V., Brito, J., Brito, L., and Duran, A. (2012). An exploratory study on the use of collaborative riding based on gamification as a support to public transportation. In SBSC, pages 84-93. IEEE Computer Society. 